\title{
Sofrimento psíquico e a universidade em tempos de crise estrutural
}

Psychic suffering and the university in times of structural crisis

Thiago Marques Leão*

Aurea Maria Zöllner Ianni**

Carine Sayuri Goto***

\begin{abstract}
Resumo - O artigo discute o impacto subjetivo das transformações sociais contemporâneas, pelo fenômeno do sofrimento psíquico na universidade. A sociedade contemporânea é marcada pelos processos de individualização e subjetivação dos riscos socialmente produzidos, conforme as instituições típicas da sociedade industrial se mostram incapazes de lidar com os riscos que produzem. Tendo em vista a perda de referências de significação social e de instituições mediadoras das relações entre o indivíduo e a sociedade, há um crescente sentimento de insegurança e sofrimento. As contradições e impasses socialmente produzidos são percebidos como fracasso pessoal, e é por esta perspectiva que se tentará lidar com o sofrimento psíquico também na universidade, seja pelo viés clínico institucional ou transformando o sofrimento em um objeto de gestão empresarial nas universidades operacionais. Para lidar com o sofrimento entre estudantes é preciso pensá-lo para além de sua dimensão individual e compreender os processos sociais de gênese e significação da experiência de sofrimento.

Palavras-chave: sofrimento psíquico; individualização; universidade; sociedade de risco; contrarreformas.
\end{abstract}

\begin{abstract}
This article discusses the subjective impact of contemporary social transformations through the phenomenon of psychic suffering in the university. Contemporary society is marked by the processes of individualization and subjectivation of socially produced risks, as typical
\end{abstract}

\footnotetext{
* Mestre e doutor em Ciências pela Faculdade de Saúde Pública da Universidade de São Paulo (FSP/USP). PósDoutorando junto ao departamento de Política, Gestão e Saúde da FSP/USP. Pesquisador do Grupo de Pesquisa "Teoria Social, Mudanças Contemporâneas e Saúde" (CNPq-FSP/USP) e do Grupo de Pesquisa "Direitos Humanos, Direito à Saúde e Família" (CNPq/Ucsal). E-mail: thmleao@usp.br. ORCID: https://orcid.org/0000-0003-24029898.

** Cientista social pela USP, mestre e doutora em Ciência Ambiental pela Universidade Estadual de Campinas. Livre-Docência em Ciências Sociais em Saúde pela Faculdade de Saúde Pública (FSP/USP). É docente da FSP/ USP e credenciada junto ao Programa de Pós-Graduação em Saúde Pública e ao Programa de Pós-Graduação em Mudança Social e Participação Política da Escola de Artes e Humanidades (EACH/USP). E-mail: aureanni @usp.br. ORCID: https://orcid.org/0000-0003-1366-8651.

*** Psicóloga e mestre em Psicologia pela Universidade Estadual Júlio de Mesquita Filho (Unesp). Psicanalista e supervisora clínico-institucional. Integrante do Laboratório Transdisciplinar de Intercessão-Pesquisa em Processos de Subjetivação e Subjetividade Saúde (Latippss). E-mail: carinesayuri@yahoo.com.br. ORCID: https://orcid.org/ 0000-0003-0008-549x.
} 


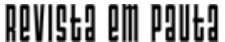

\} SOFRIMENTO PSÍQUICO E A UNIVERSIDADE - LEÃO, T. M.; IANNI, A. M. Z.; GOTO, C. S. \}

DOI: $10.12957 /$ REP.2019.45212

institutions of industrial society are unable to deal with the risks they produce. In view of the loss of references of social significance and of institutions that mediate relations between the individual and society, there is a growing sense of insecurity and suffering. Socially produced contradictions and impasses are perceived as personal failure, and it is from this perspective that one will try to deal with psychic suffering at the university, either by institutional clinical bias or by turning suffering into an object of business management in operational universities. To deal with suffering among students, it is necessary to think beyond its individual dimension and to understand the social processes of genesis and meaning of the experience of suffering.

Keywords: psychic suffering; individualization; university; venture society; counterreformation.

\section{Introdução}

Este artigo discute o impacto subjetivo das transformações sociais contemporâneas, em sua expressão fenomênica, como experiência social (individualmente generalizada) de sofrimento psíquico, abordando especificamente o sofrimento no ambiente universitário. Este evidencia de forma imediata as pressões, contradições e impasses da vida universitária, em uma sociedade individualizada, do consumo e do desempenho.

Além do fenômeno diretamente observável, o sofrimento é expressão de uma metamorfose estrutural da sociedade, resultante da crise e deslocalização das instituições sobre as quais se ancorava a sociedade industrial. Não se trata apenas de uma crise conjuntural ou de mudanças pontuais nas dinâmicas sociais, mas de uma transformação radical em todos os aspectos da vida social, que altera o funcionamento das instituições. Além disso, também modifica "nossa maneira de estar no mundo - a maneira como vivemos no mundo, como pensamos o mundo e como tentamos agir sobre o mundo por meio da ação social e política" (BECK, 2017, p. 16).

Vivemos em uma sociedade em constante transformação, na qual há uma crescente subjetivação e individualização dos riscos e contradições socialmente produzidas; em outras palavras, estes riscos e contradições são cada vez mais percebidos como fracasso pessoal e descolados de seu contexto social e institucional, para se transformarem em "novas formas de risco pessoal: somam-lhes novas formas de 'atribuição de culpa'" (BECK, 2010, p. 200). As crises produzidas social e institucionalmente são percebidas como crises individuais à medida que se fragilizam as instituições e redes de proteção social, cada vez menos preparadas para lidar com o sofrimento e o adoecimento psíquicos. As respostas ou reações ao sofrimento, portanto, também se organizam de forma individualizada e estando aquém da sua complexidade. 


\section{ReVIStg am P puttg}

\} SOFRIMENTO PSÍQUICO E A UNIVERSIDADE - LEÃO, T. M.; IANNI, A. M. Z.; GOTO, C. S. \}

DOI: $10.12957 /$ REP.2019.45212

Neste sentido, as respostas institucionais tendem a adotar, em linhas gerais, uma perspectiva essencialmente individual, seja pelo viés clínico, seja pelo viés da "auto-administração" - como aqui o denominaremos. $O$ viés clínico das respostas institucionais presume um sentido totalizador da clínica (DONNANGELO, 1979), capaz de transcender os limites do ato individual de saúde e atingir as causas sociais do sofrimento. Assim, àquele que sofre e adoece é ofertado o atendimento individual (ANDRADE, 2017), tomando as manifestações mais agudas de sofrimento sob o marco do desvio ou da anormalidade.

Não se consideram o ambiente ou as práticas institucionais, os eventuais desafios acadêmicos, as violências simbólicas e físicas, as insuficiências econômicas e assim por diante - aos quais tampouco poderá a clínica responder. Simplesmente, quando há serviços de saúde mental ligados às universidades, quem adoece é encaminhado à clínica individual para depois retornar às engrenagens da máquina que o adoeceu e que permanece intocada.

O viés da autoadministração transforma a experiência do sofrimento em objeto administrativo, isto é, aborda o sofrimento a partir de uma "racionalidade administrativa" (CHAUÍ, 2014), que não se pergunta sobre o porquê do sofrimento ou sobre seu contexto social de emergência, mas busca dar respostas organizativas a este: uma melhor organização das atividades cotidianas do estudante, repensar a distribuição de carga horária, metodologias de estudo, memorização e sono, e assim por diante. O viés da autoadministração nas respostas institucionais se assemelha às técnicas do discurso gerencial de empresas ou dos livros de autoajuda. Além disso, normalmente "se apresentam como saberes psicológicos, com um léxico especial, autores de referência, metodologias particulares, modos de argumentação de feição empírica e racional" e como técnicas de autotransformação individual a partir de princípios básicos (DARDORT; LAVAL, 2016, p. 339). Tudo conspira para que o indivíduo, por si mesmo, promova uma melhora em seu desempenho e produtividade (laboral ou acadêmica) e atue como protagonista de sua própria biografia.

Este discurso reforça a responsabilidade e (auto)culpabilização individual sobre o sofrimento - sofre quem não é resiliente o bastante, quem não se organizou adequadamente, quem não sabe como estudar etc. - e afasta a análise de eventuais fatores supraindividuais que possam estar ligados à experiência de sofrimento. Apresenta, portanto, uma gramática neoliberal do sofrimento, em que não há sociedade, conflitos ou contradições sociais, mas apenas o indivíduo que sofre e que, por mérito próprio, deve superar o sofrimento pela autoadministração e aprimoramento pessoais.

É certo que fatores individuais, bem como situações ligadas ao ambiente, funcionamento e práticas acadêmicas, devem ser levados em consideração como possíveis aspectos da experiência de sofrimento. Mas assumi-las como causas únicas e necessárias, ou abordá-las de um ponto 


\section{ReVIIStR PMI PDUtD}

\} SOFRIMENTO PSÍQUICO E A UNIVERSIDADE - LEÃO, T. M.; IANNI, A. M. Z.; GOTO, C. S. \}

DOI: $10.12957 /$ REP.2019.45212

de vista estritamente individual, é uma leitura reducionista e, portanto, equivocada. Junto a questões eminentemente individuais e singulares, o sofrimento no ambiente universitário envolve também dimensões socioestruturais, coletivas e institucionais. Isto é, ao mesmo tempo em que duas pessoas não experimentam o sofrimento de forma absolutamente igual, há também algo comum, algo coletivamente individualizado. O sofrimento individual pode estar relacionado a (i) questões coletivas, opressões ou violências específicas de determinados grupos (renda e escolaridade, gênero, raça e sexualidade, pessoas com deficiência etc.), a (ii) questões socioestruturais e econômicas (contrarreformas, mudanças das condições objetivas de vida e de consciência, modo de produção capitalista, ciclos e crises político-ideológicas etc.) e a (iii) relações ligadas diretamente ao contexto da universidade (produtivismo acadêmico, jornada de trabalho e estudo, assédio moral e sexual, precarização das condições de trabalho e estudo etc.).

Ao pensarmos o sofrimento nestas quatro dimensões, não podemos desconsiderar como elas se relacionam e se determinam mutuamente, como intensificam ou aliviam o impacto sobre os estudantes. Estas dimensões (individual, social, coletiva e institucional) são indissociáveis, multideterminantes e multideterminadas, para além do quadro específico do sofrimento psíquico. Nosso quadro de análise destas questões é a Sociedade de Risco e o processo de Individualização, discutidos pelo sociólogo alemão Ulrich Beck (2010).

\section{Sobre a modernização reflexiva e o processo de individualização}

Os contornos do sofrimento psíquico, em que pese seu caráter subjetivo, são eminentemente sociais. A maneira como daremos significado so sofrimento será determinada pelas formas e pelos referenciais sociossimbólicos historicamente situados à medida que nós, igualmente, somos sujeitos históricos. Assim, é importante que contextualizemos nosso marco de leitura social sobre o fenômeno, a partir das profundas mudanças estruturais pelas quais passou a sociedade ocidental moderna nas últimas décadas. Beck $(2010,2012)$ analisou estas mudanças pelo que denominou de Modernização Reflexiva, isto é, um processo de modernização da modernidade, pela autotransformação das instituições e relações da sociedade industrial, atravessada por contradições e efeitos colaterais não planejados.

O processo acelerado de transformação, típico do dinamismo da sociedade industrial, remonta ao intenso contexto histórico de mudanças socioculturais e político-econômicas de alcance global, que culmina no paradigmático ano de 1989, com o fim do antagonismo Oriente-Ocidente, a hegemonia do projeto capitalista e a dissolução do "inimigo ao Leste" (HOBSBAWM, 2009; BECK, 2010, 2012). Com a queda do Muro de Berlim, 


\section{ReVIStg am P puttg}

\} SOFRIMENTO PSÍQUICO E A UNIVERSIDADE - LEÃO, T. M.; IANNI, A. M. Z.; GOTO, C. S. \}

DOI: $10.12957 /$ REP.2019.45212

cai o "inimigo" da democracia liberal, e a sociedade mundial, que vivia seus regimes políticos pautada pela luta bipolar e por antagonismo recíprocos, perdeu, em grande parte, seu direcionamento e bandeiras de ação. Com as transformações sociais das últimas décadas, os indivíduos perderam suas certezas, marcos de significação sociossimbólicos e espaços de mediação e coletivização dos riscos sociais. Desse modo, foram remetidos à "solidão da autorresponsabilidade, da autodeterminação e da autoameaça do viver e do amar, para as quais não estão preparados, tampouco equipados pelas condições externas" (BECK; BECK-GERNSHEIM, 2017, p. 18).

À medida em que há uma dissolução das instituições, seguranças e referenciais sociossimbólicos ${ }^{1}$ - determinantes na condução da vida individual, nos processos de subjetivação e intermediação entre indivíduos e realidade social -, os indivíduos são convocados a avaliar os riscos, tomar decisões e responsabilizar-se individualmente pelas consequências destas escolhas. Mas o processo de modernização reflexiva implodiu o

sistema intrassocial de coordenadas da sociedade industrial: sua compreensão da ciência e da tecnologia, os eixos entre os quais se estende a vida das pessoas: família e profissão, a distribuição e a separação entre política democraticamente legitimada e subpolítica. (BECK, 2010, p. 107).

Sobrecarregados pela (auto)responsabilização individual e pela perda de "coordenadas sociais", vivenciamos ansiedade, impasses e inação, isto é, sentimo-nos incapazes de decidir e agir. Estes não são impasses apenas íntimos e particulares, mas radicalmente sociais: o sofrimento nunca é puramente individual, como se houvesse indivíduos sofrendo fora da sociedade. As escolhas com que nos confrontamos precisam ser avaliadas, negociadas, justificadas e sustentadas como riscos assumidos individualmente, tornando as identidades cada vez mais inconstantes e inseguras. Este é o quadro duplo e contraditório do processo sócio-histórico de Individualização: os indivíduos se desoneram dos vínculos tradicionais da sociedade industrial moderna, mas são pressionados pelas demandas e regulações do mercado de trabalho e das necessidades de consumo e subsistência, enquanto lidam com os riscos socialmente produzidos.

Hoje, o indivíduo se converte em unidade reprodutiva e de (auto)significação da sociedade, à medida que há uma individualização da rede de referências sociossimbólica e dissolução das instituições e instâncias sociais identificadas com o Grande Outro na modernidade industrial (SALECL, 2012). A biografia das pessoas passa a ser construída pelo imperativo de escolhas individuais, uma autobiografia reflexiva baseada em riscos e incertezas, na qual

\footnotetext{
${ }^{1}$ É mister explicar que a ideia de dissolução não significa desaparecimento, mas a deterioração das formas sociais que tradicionalmente delimitariam o fenômeno e sua metamorfose contemporânea.
} 


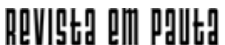

\} SOFRIMENTO PSÍQUICO E A UNIVERSIDADE - LEÃO, T. M.; IANNI, A. M. Z.; GOTO, C. S. \}

DOI: $10.12957 /$ REP.2019.45212

elas se veem obrigadas [...], sob pena de prejuízo material, a construir uma existência própria por meio do mercado de trabalho, da formação e da mobilidade e, se necessário, impor e conservá-la em detrimento dos laços de família, parceria e vizinhança. (BECK; BECK-GERNSHEIM, 2017, p. 18).

Sem desconsiderar a dimensão ideológica do sujeito neoliberal e sua falsa consciência de classe (DARDOT; LAVAL, 2016), na sociedade individualizada os indivíduos são obrigados a agir e ver-se como eixo central de sua ação (motor, meio e objetivo de ação), sob risco de desvantagem permanente e, no limite, de cair no abismo material e social decorrente da exclusão do mercado de trabalho (BECK, 2010; BECK; BECK-GERNSHEIM, 2017).

\section{Individualização subjetiva e sofrimento psíquico}

Como explica lanni (2014, p. 216), "toda configuração social de vida e trabalho compreende sempre quadros mentais de referência. As atividades dos indivíduos e coletividades compreendem sempre modos de ser, agir, pensar e imaginar" historicamente determinados. Estes quadros mentais mudam conforme muda a sociedade, mas não apenas conjunturalmente. Ainda que se possa reagir de forma diversa em situações adversas e que fogem à normalidade (situações de crise conjuntural), as mudanças subjetivas acompanham as mudanças objetivas dos modos de vida e se dão como processo sócio-histórico de formação dialético.

Assim, na contemporaneidade, a transformação social (individualização) das condições objetivas de vida implica uma transformação (individualização) também subjetiva. Pensar o mundo sob uma perspectiva materialista-dialética significa compreender a conexão necessária entre as estruturas social e política, os modos de produção e a subjetividade. Segundo Marx e Engels (2007, p. 93-94),

as formações nebulosas na cabeça dos homens são sublimações necessárias de seu processo de vida material [...], os homens, ao desenvolverem sua produção e seu intercâmbio materiais, transformam também, com esta sua realidade, seu pensar e os produtos de seu pensar.

As transformações nas condições objetivas de vida em sociedade são acompanhadas de transformações subjetivas - as formas de sofrer, sentir, produzir, consumir, pensar (a si mesmo e) o mundo, atuar politicamente e assim por diante. É um fenômeno distinto da pura ideologia, e que resulta do processo sócio-histórico e material de subjetivação. Como explica Horkheimer (2015, p. 21), não se trata apenas de manipulações ideológicas, "mas, sim, a estrutura psíquica total destes grupos, isto é, o caráter de seus 


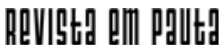

\} SOFRIMENTO PSÍQUICO E A UNIVERSIDADE - LEÃO, T. M.; IANNI, A. M. Z.; GOTO, C. S. \}

DOI: $10.12957 /$ REP.2019.45212

membros se renova constantemente em relação com seu papel no processo econômico".

Neste sentido, as transformações no mundo do trabalho, na família e nas relações de gênero, na política local e global etc., relaciona-se dialeticamente com uma transformação profunda nas formas como os indivíduos relacionam-se consigo mesmos, com outros indivíduos e com as instituições (LEÃO, 2018). O processo de modernização reflexiva também atinge a ordem sociossimbólica, promovendo um processo que poderíamos chamar de subjetivação reflexiva.

A dissolução reflexiva da rede de referências sociossimbólica se dá pela dissolução e desincorporação das instituições sociais identificadas com esta rede na modernidade industrial: família, Estado, atribuições de gênero, nacionalidade, classe social, saber científico, sexualidade e assim por diante. Estes laços tradicionais que limitavam a liberdade individual também ofereciam um sentimento de segurança, pertencimento, estabilidade e identidade interior. Em seu lugar, tem-se a percepção de que não há ordenação simbólica e de que o indivíduo está abandonado à própria liberdade.

Os imperativos de (auto)construção biográfica e (auto)responsabilidade individual são incorporados subjetivamente e, assim, balizam as relações sociais e a autocompreensão individual. Na medida em que as novas formas de enquadramento e reintegração se tornam egocentradas, a possibilidade de simbolização das experiências se desloca para o próprio indivíduo e se esvanece.

A subjetivação reflexiva faz emergir subjetividades de risco, com indivíduos que se percebem em uma relação imediata com os riscos biográficos (de fracasso e sucesso) e que se sentem em contato sem mediação entre indivíduo e sociedade, "no sentido de que crises sociais se manifestam como crises individuais e já não são percebidas em sua dimensão social" (BECK, 2010, p. 147). As incertezas e inseguranças são coletivamente individualizadas, e não apenas se desestabiliza a confiança pública nas instituições e nos sistemas político e educacional, dentre outros. Ademais, há um sentimento geral de que as biografias normais se tornaram biografias de risco: se, em outras gerações, nossos pais e avós concluíram os estudos, entraram no mercado de trabalho, casaram, tiveram filhos e netos e se aposentaram em relativa segurança, hoje, ninguém mais olha para o futuro com segurança.

Sobrecarregados, os indivíduos se sentem intensamente inseguros sobre suas condições materiais de existência e sua capacidade subjetiva de lidar com isto. Tanto a subsistência material quanto os atuais sistemas de previdência dependem da participação no mercado de trabalho, sendo esta a condição objetiva para segurança social. Por sua vez, a entrada (e permanência) no mercado de trabalho é condicionada à (constante) formação acadêmico-profissional. Contudo, enquanto presenciamos o desmonte da 


\section{ReVIIStR PMI PDUtD}

\} SOFRIMENTO PSÍQUICO E A UNIVERSIDADE - LEÃO, T. M.; IANNI, A. M. Z.; GOTO, C. S. \}

DOI: $10.12957 /$ REP.2019.45212

universidade pública, a formação é cada vez mais "entendida como adestramento e transmissão rápida de conhecimentos, consignados em manuais de fácil leitura para os estudantes", concepção típica das "universidades operacionais" (CHAUÍ, 2014, p. 95). O mundo do trabalho oferece cada vez menos segurança, dada a sua crescente flexibilização, perda de estabilidade e poder negocial dos trabalhadores, distanciando-se das dinâmicas laborais da sociedade industrial.

A conjuntura político-institucional contribui para a intensificada sensação de insegurança, em meio à ascensão de governos populistas de extrema-direita e do que Beck (2003) chama de autoritarismo democrático: a combinação entre formas autoritárias e formas democráticas de governo, em que as primeiras tendem a adquirir maior importância em relação às últimas, à medida em que se forma um consenso social em torno da necessidade de promover condições de segurança a todo custo.

Ao passo que o Estado recua e os governos perdem controle sobre a economia e sobre as relações assumidas no mercado de trabalho, há uma abertura cada vez maior aos movimentos antidemocráticos de contrarreforma, tanto por parte dos governos que querem reafirmar sua (perdida) capacidade de interferir sobre a realidade social, quanto por parte dos grupos que se sentem cada vez mais inseguros e desencontrados.

As contrarreformas de caráter neoliberal destes governos contribuem para a dissolução das redes de seguranças, políticas públicas e direitos sociais. Nas palavras de Pinto (2014, p. 662), as reformas se caracterizam pela transferência de "diversas atividades para o controle do mercado, que passam a ser assumidas pelo empresariado e demais setores privados, sendo que o Estado assumirá a função de repassador de recurso e regulador dos processos", e a noção de direitos sociais é transfigurada como serviços de consumo (PEREIRA, 2009).

Em meio ao turbilhão de transformações sociais, os sentimentos de ansiedade, desamparo e desencontro entre indivíduo e sociedade não apenas se intensificaram, como se generalizaram nas mais diversas experiências de vida em sociedade. Esta subjetivação da experiência acompanha as mudanças estruturais profundas na sociedade ocidental moderna, cuja novidade "está tanto em sua extraordinária rapidez quanto em sua universalidade" (HOBSBAWM, 1995, p. 283), e expressa o impacto destas transformações sobre o indivíduo.

Se o sofrimento e adoecimento psíquicos parecem uma consequência direta de eventos e crises conjunturais - depressão econômica, convulsões políticas, guerras, desemprego, surtos epidêmicos e assim por diante -, Salecl (2005, p. 11) alerta que "não devemos esquecer de que [a ansiedade] tem origem na percepção alterada do sujeito em relação a si mesmo, bem como das mudanças de sua posição dentro da sociedade como um todo". Nas palavras de Beck (2013, p. 27), momentos de discrepância entre as expectativas e a realidade social levam à 
Perplexidade, medo, não saber, frustração, inquietação, mas também desejo de mudança - tudo isto é típico destas situações confusas, nas quais as expectativas das pessoas deixaram de ser compatíveis com os arranjos institucionais que deveriam satisfazê-las.

Os momentos de transição cultural e transformações sociais podem abalar radicalmente os quadros sociossimbólicos de referência individual e das coletividades, levando a sentimentos de desamparo e inadequação, ansiedade e entristecimento profundos, bem como à perda de perspectivas. As transformações materiais das condições objetivas de vida são, assim, acompanhadas por transformações subjetivas e por sofrimento.

\section{Universidade e a gramática do sofrimento}

Não há experiência social sem sofrimento e talvez não seja desejável que haja, sob pena de os indivíduos enfrentarem a imobilidade e o comodismo, a perda de horizontes e da busca para melhorar a si mesmos e à sociedade. Como afirma Dunker (2015, p. 219), vivemos na "linha de corte entre o sofrimento que deve ser suportado como necessário e o sofrimento que é contingente e pode ser modificado". Podemos pensar esta linha de corte tanto quanto à dimensão subjetiva do sofrimento suportável, quanto às determinações social e ideológica sobre o que deve ser suportado pelo indivíduo (e noções como resiliência e perseverança legitimam e recompensam sociossimbolicamente esta conformidade do indivíduo aos valores e exigências socioideológicas). Mas não precisa ser suportado sem risco de reprovação social e pode ou não ser modificado. Assim, também a própria ação política se submete a essa subjetivação dos riscos sociais. À medida em que contradições e injustiças sociais são encaradas como crises individuais, buscam-se respostas individuais (no mais das vezes medicalizantes) e perde-se de vista o caráter social e político destas mesmas demandas, bem como a possibilidade de organização e luta coletiva por elas.

Sem generalizações, no âmbito acadêmico encontraremos estudantes que parecem politicamente indiferentes ou que lidam com a política como algo personalista e subjetivo, cujas contradições e impasses, simultaneamente, colocam em xeque sua cidadania e seus sentimentos e realização pessoais: estudantes que demandam atenção e cuidado, mas que não se mobilizam, necessariamente, no ambiente acadêmico. Ou, ainda, que se mobilizam em torno de "um posicionamento genérico de demanda que espera atendimento sem querer propriamente, impor decisões" (HABERMAS, 2003, p. 246). Isto se deve, em grande medida, às constantes exigências, sobrecarga e ao imperativo de escolhas individuais, mas que levam a sentimentos de inadequação, desamparo e impotência como sintomas desse desencontro entre experiências sociais e subjetivas, resultante das traumáticas mudanças sociais das últimas décadas. 


\section{ReVIIStR PMI PDUtD}

\} SOFRIMENTO PSÍQUICO E A UNIVERSIDADE - LEÃO, T. M.; IANNI, A. M. Z.; GOTO, C. S. \}

DOI: $10.12957 /$ REP.2019.45212

Neste sentido, balizas ideológicas e formas sócio-históricas ditarão a gramática deste sofrimento: o que é ou não suportável para o indivíduo, o que pode (deve) ou não ser modificado (e como), o que precisa ser aceito e sob que circunstâncias é aceitável ou não sofrer. Sem dúvidas, a experiência de sofrimento não está sujeita a estes imperativos sociais e o sofrimento individual, bem como aquilo que os indivíduos (não) suportarão, não será condicionado pela gramática neoliberal do sofrimento.

Contudo, a forma como damos significado à experiência de sofrimento é social e historicamente determinada, obedecendo, no marco contemporâneo da Sociedade de Risco, ao imperativo geral de (auto)responsabilização individual, bem como à "obrigação de planejar e concretizar uma biografia profissional, o que pressupõe uma biografia educacional, [e] de satisfazer as correspondentes exigências de mobilidade requeridas no mercado de trabalho" (BECK; BECK-GERNSHEIM, 2017, p. 18).

A educação e o mercado de trabalho são condições institucionais orientadas ao indivíduo, e não ao coletivo; é isto que significa a Individualização:

uma dinâmica institucional direcionada ao indivíduo, não ao grupo [...]. Coisa que de sua parte impõe decisões, negociações, conflitos, e cuja característica é: agora muitos problemas basicamente condicionados pelo institucional são descarregados nos indivíduos. (BECK, 2003, p. 69).

Ao pensar o quadro específico do sofrimento entre estudantes, não estamos com isto nos referindo apenas a aspectos institucionais internos à universidade e à formação acadêmica. Mas - além das cobranças, do ritmo extenuante, da falta de políticas de permanência, das violências variadas (de gênero, raça, sexualidades) praticadas por professores (assédio sexual e moral) ou por colegas (discriminações, bullying) - estes estudantes têm que lidar com transformações e crises da família, da dissolução de redes de segurança e garantia de direitos sociais, nas relações interpessoais, no mundo do trabalho e no próprio funcionamento da universidade. A formação superior deixa de garantir a chance do emprego e possivelmente de empregos estáveis e bem-remunerados, se comparados com a população em geral.

Viu-se no Brasil um crescimento inédito no ensino superior no período de 2003 a 2010, ainda que as instituições privadas tenham respondido, em 2009, por um total de 89,4\% das instituições de ensino superior no país (ABEPSS; CFESS, 2011). Apenas de 1999 a 2004, o número de instituições públicas de ensino superior ${ }^{2}$ passou de dezesseis para 144 (BRASIL, 2005); em 2017, esse número saltou para 296 instituições de educação superior públicas $(12,1 \%)$ e 2.045.356 matrículas $(24,7 \%)$, contra 1.335.177, em 2007 (BRASIL, 2017).

2 Entre universidades, centros universitários, faculdades e institutos federais (IFs) e centros federais de educação tecnológica (Cefets). 


\section{ReVIStg am P puttg}

\} SOFRIMENTO PSÍQUICO E A UNIVERSIDADE - LEÃO, T. M.; IANNI, A. M. Z.; GOTO, C. S. \}

DOI: $10.12957 /$ REP.2019.45212

Porém, as portas que foram abertas na educação superior são fechadas no mercado de trabalho: no segundo trimestre de 2018, a taxa de desemprego entre jovens ( 18 a 24 anos) era de $26,6 \%$ e, portanto, mais que o dobro da taxa de desemprego da população em geral, que foi de 12,4\%, segundo dados do Instituto Brasileiro de Geografia e Estatística (IBGE BRASIL, 2019). Assim, retomando Beck (2010, p. 220), há um "número crescente de formandos em todos os cursos [que] veem-se lançados à arriscada terra de ninguém dos subempregos precários que se estendem entre educação e trabalho", enfrentando frustrações, culpa e fracasso na transição para a vida profissional após tanto investimento em sua formação universitária.

Vivemos o fim das promessas de um percurso da educação para o mercado de trabalho, dos cursos de (pós-)graduação para o emprego com garantias de uma relativa segurança e estabilidade, dando lugar a uma era de "ansiedade estrutural" (SUZUKI et al., 2010). O desemprego estrutural, associado à generalização do subemprego ou das relações precarizadas de trabalho, tem um impacto radical sobre o sistema de ensino e sobre os estudantes: falta de perspectiva de emprego, desmonte de políticas de permanência da universidade, cargas horárias incompatíveis com demandas de trabalho e familiares, assim como grandes deslocamentos e gastos entre as periferias e os centros urbanos.

Estas dissonâncias podem passar desapercebidas para professores e gestores, ou mesmo serem dissimuladas sob demandas de autoadministração e maior organização e empenho por parte dos estudantes. Contudo, não passam despercebidas para estudantes, "que, no mais tardar, ao deixar a escola, encontrarão fechadas as portas do sistema empregatício e evidentemente já não são capazes de antecipar isso mesmo durante seu período escolar" (BECK, 2010, p. 218-219).

Milhares de jovens e trabalhadores buscam ampliar seus horizontes sociais e econômicos para a fim de encontrar a inserção no mercado de trabalho pela educação (ABEPSS; CFESS, 2011), e permanecem em escolas e cursos de formação suplementar para evitar o desemprego. Entretanto, o "desemprego estrutural duradouro acaba tornando contraditória a situação no sistema educacional profissionalizante", que leva estudantes a duvidarem de si mesmos, do sistema de ensino e do mercado de trabalho. Um "processo que, por razões psicológicas e políticas, é imensamente preocupante" (BECK, 2010, p. 219).

Ainda quando empregados após a graduação, assistentes sociais, psicólogos, terapeutas ocupacionais e outros profissionais de saúde que lidam diretamente com grupos e populações marginalizados enfrentarão desafios e demandas irrealizáveis frente à mudança estrutural do mundo do trabalho. Além disso, terão que lidar com a frustração e a (auto)culpabilização que estas barreiras estruturais impõem à sua atuação micropolítica. Profissionais "que se esforçam para a 'reabilitação' e a 'integração' dessas 


\section{ReVIIStR PMI PDUtD}

\} SOFRIMENTO PSÍQUICO E A UNIVERSIDADE - LEÃO, T. M.; IANNI, A. M. Z.; GOTO, C. S. \}

DOI: $10.12957 /$ REP.2019.45212

pessoas e grupos - o que implica naturalmente integrar mais desempregados ao sistema empregatício -, acabam por colocar em risco a efetividade e a autoridade de seu próprio trabalho" (BECK, 2010, p. 220), enquanto estes impasses e limites da assistência são percebidos como fracassos pessoais e depositados sobre os profissionais individualmente.

As políticas de austeridade, as privatizações e flexibilizações de leis trabalhistas e o desemprego estrutural intensificam as dificuldades na transição entre formação e trabalho para os formandos do ensino superior, cuja mão de obra não é absorvida ou é absorvida muito aquém dos investimentos e expectativas ligadas ao trabalho após a universidade. As pressões para se submeter a relações precárias de trabalho afetam subjetivamente os profissionais e os estudantes, que seguem um movimento pendular de esperanças e frustrações quanto às possibilidades de melhoria de vida através da formação ou aperfeiçoamento profissional.

\section{Considerações finais}

Junto à generalização do subemprego ou das formas precarizadas que assumem a relação de emprego e trabalho, a crescente individualização dos riscos ocupacionais marca uma mudança estrutural na forma trabalho. Família e trabalho, como coordenadas sociossimbólicas de formação da subjetividade, perdem suas antigas garantias e funções mediadoras. Se houve ganhos de regulação, direitos e garantias institucionais ligadas ao trabalho ao longo dos anos, com a flexibilização temporal (jornada) e espacial (local) do trabalho há uma privatização dos riscos laborais de adoecimento físico e psíquico. Ou seja, riscos socialmente produzidos são depositados sobre os indivíduos, que devem avaliá-los, enfrentá-los e se responsabilizar por suas consequências individualmente. Este é o horizonte dos estudantes, que não passam incólumes ao processo de generalização das incertezas ocupacionais.

A reconformação das universidades em universidades operacionais, regidas por ideais de gestão, controle e êxito, eficiência e racionalidade administrativa, intensificam a sobrecarga e a (auto)culpabilização individual, com suas metas e cobranças, seu funcionamento maquínico e empresarial, bem como com seu imaginário de eficiência e organização impostos também aos estudantes, que se transmutam em sujeitos empresariais (DARDOT; LA$V A L, 2016)$. Estes devem se autoadministrar, avaliando, decidindo e se responsabilizando individualmente por contradições institucionais e sociais convertidas em fracasso pessoal.

Ao mesmo tempo, a universidade perde seu caráter de mediação entre os estudantes e a realidade social, na medida em que os atira ao abandono do imperativo da responsabilidade individual e desempenho. Dessa maneira, ela se estrutura como espaço de produção serializada de mão de 


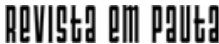

\{ SOFRIMENTO PSÍQUICO E A UNIVERSIDADE - LEÃO, T. M.; IANNI, A. M. Z.; GOTO, C. S. \}

DOI: $10.12957 /$ REP.2019.45212

obra acrítica, adestrada e alheia às "ideias de investigação, interrogação, crítica e criação" (CHAUÍ, 2014, p. 95); portanto, sujeita à gramática neoliberal do sofrimento e incapaz de questionar os "porquês" e dimensões supraindividuais dos impasses que enfrenta.

A gramática neoliberal do sofrimento, por um lado, transfigura riscos e contradições sociais em fracassos e culpa pessoal; por outro lado, naturaliza estas mesmas contradições e as descola de seu contexto sociopolítico. Portanto, isto as retira das possibilidades de disputa política destas contradições. Os processos de Individualização e subjetivação dos riscos sociais são os grandes pilares desta gramática, e para lidar com o sofrimento para além deste recorte individualista e medicalizado, faz-se necessário identificar, compreender e discutir os contornos destes processos. 


\section{ReVIIStR PMI PDUtD}

\} SOFRIMENTO PSÍQUICO E A UNIVERSIDADE - LEÃO, T. M.; IANNI, A. M. Z.; GOTO, C. S. \}

DOI: $10.12957 /$ REP.2019.45212

\section{Referências}

ABEPSS; CFESS. As entidades do Serviço Social brasileiro na defesa da formação profissional e do projeto ético-político. Serviço Social e Sociedade, São Paulo, n. 108, out./dez. 2011.

ANDRADE, R. O. Distúrbios na academia. Pesquisa Fapesp, São Paulo, ano 18, n. 262, dez. 2017.

BECK, U. Liberdade ou capitalismo: Ulrich Beck conversa com Johannes Willms. São Paulo: Unesp, 2003.

BECK, U. Sociedade de Risco: rumo a uma outra modernidade. São Paulo: Editora 34, 2010.

BECK, U. A reinvenção da política: rumo a uma teoria da modernização reflexiva. In: BECK, U.; GIDDENS, A.; LASH, S. Modernização Reflexiva: política, tradição e estética na ordem social moderna. São Paulo: Editora Unesp, 2012.

BECK, U. A Europa alemã: de Maquiavel a "Merkievel": estratégias de poder na crise do euro. Lisboa: Edições 70, 2013.

BECK, U. A metamorfose do mundo: como as alterações climáticas estão a transformar a sociedade. Lisboa: Edições 70, 2017.

BECK, U.; BECK-GERNSHEIM, E. O caos totalmente normal do amor. Rio de Janeiro: Editora Vozes, 2017.

BRASIL. Ministério da Educação. Instituto Nacional de Estudos e Pesquisas Educacionais Anísio Teixeira (Inep). Censo da educação superior 2004. Brasília, DF: MEC, 2005.

BRASIL. Ministério da Educação. Instituto Nacional de Estudos e Pesquisas Educacionais Anísio Teixeira (Inep). Censo da educação superior 2017. Brasília, DF: MEC, 2017.

BRASIL. Instituto de Pesquisa Econômica Aplicada (Ipea). Mercado de trabalho. 2019. Disponível em: http://www.ipea.gov.br/cartadeconjuntura/ index.php/tag/taxa-de-desemprego/. Acesso em: mar. 2019.

CHAUÍ, M. A ideologia da competência. São Paulo: Editora Fundação Perseu Abramo, 2014.

DARDOT, P.; LAVAL, C. A nova razão do mundo: ensaio sobre a sociedade neoliberal. São Paulo: Boitempo, 2016.

DONNANGELO, M. C. Saúde e sociedade. In: DONNANGELO, M. C.; PEREIRA, L. Saúde e sociedade. São Paulo: Duas Cidades, 1979.

DUNKER, C. Mal-estar, sofrimento e sintoma: uma psicologia do Brasil entre muros. São Paulo: Boitempo, 2015. 


\section{ReVIStg a d P p putt}

\} SOFRIMENTO PSÍQUICO E A UNIVERSIDADE - LEÃO, T. M.; IANNI, A. M. Z.; GOTO, C. S. \}

DOI: $10.12957 /$ REP.2019.45212

HABERMAS, J. Mudança estrutural na esfera pública: investigações quanto a uma categoria da sociedade burguesa. Rio de Janeiro: Tempo Brasileiro, 2003.

HOBSBAWM, E. Era dos extremos: o breve século XX - 1914-1991. São Paulo: Companhia das Letras, 1995.

HOBSBAWM, E. O novo século: entrevista a Antonio Polito. São Paulo: Companhia das Letras, 2009.

HORKHEIMER, M. Teoria crítica (I): uma documentação. São Paulo: Perspectiva, 2015.

IANNI, O. A era do globalismo. Rio de Janeiro: Civilização Brasileira, 2014. LEÃO, T. Loucura, psiquiatria e sociedade: o campo da saúde mental coletiva e o processo de individualização no Brasil. Tese (Doutorado em Ciências) Faculdade de Saúde Pública da Universidade de São Paulo, USP, São Paulo, 2018.

MARX, K., ENGELS, F. A ideologia alemã. Crítica da mais recente filosofia alemã em seus representantes Feuerbach, B. Bauer e Stirner, e do socialismo alemão em seus diferentes profetas (1845-1846). São Paulo: Boitempo, 2007. PEREIRA, D. Mercantilização do ensino superior, educação a distância e Serviço Social. Revista Katálysis, Florianópolis, v. 12, n. 2, jul./dez. 2009.

PINTO, M. Condições sócio-ocupacionais do trabalho docente e a formação profissional. Serviço Social e Sociedade, São Paulo, n. 120, out./dez. 2014.

SALECL, R. Sobre a ansiedade. São Leopoldo: Editora Unisinos, 2005.

SALECL, R. Sobre a felicidade: ansiedade e consumo na era do hipercapitalismo. São Paulo: Alameda, 2012.

SUZUKI, M. et al. Individualizing Japan: searching for its origin in first modernity. British Journal of Sociology, London, v. 3, n. 61, set. 2010.

DOI: $10.12957 /$ rep.2019.45212

Recebido em 01 de abril de 2019.

Aprovado para publicação em 02 de maio de 2019.

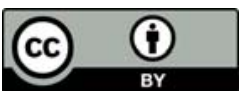

A Revista Em Pauta: Teoria Social e Realidade Contemporânea está licenciada com uma Licença Creative Commons Atribuição 4.0 Internacional. 